\title{
Zvanična i individualna istorija u romanu Deca ponoći Salmana Ruždija
}

\author{
Milica S. Stanković* \\ Univerzitet u Kragujevcu, Filološko-umetnički fakultet, Centar za proučavanje jezika i \\ književnosti
}

Ključne reči:
istorija
fikcija
istina
istoriografska
metafikcija
zvanična istorija
individualna istorija

\begin{abstract}
Apstrakt
Tema mnogih romana druge polovine XX veka jeste složen odnos između istorije i fikcije koji se, premda razmatran još od antičkih vremena, posebno problematizuje u epohi postmoderne. Jedno od ključnih književnih dela postmodernizma, koje predstavlja izraziti primer žanra istoriografske metafikcije čije je odlike definisala Linda Hačion (Linda Hutcheon) u svojoj Poetici postmodernizma (A Poetics of Postmodernism, 1988), jeste roman Deca ponoći (Midnight's Children, 1981) Salmana Ruždija (Salman Rushdie). Cilj ovog rada jeste da se, oslanjajući se na teorijske postavke u kojima se razmatra problem spoznaje književne istine koji se nalazi u središtu problematičnog odnosa između istorije i fikcije, analizira ovo delo, sa posebnim osvrtom na način na koji se u njemu problematizuje odnos između zvanične i individualne verzije istorijske istine. (примьено: 29. септембра 2021; прихваћено: 3. новембра 2021)
\end{abstract}

www.anali.fil.bg.ac.rs 


\section{Uvod}

Govoreći o Deci ponoći u eseju „Imaginarni zavičaji“, Salman Ruždi (2007: 27) ovaj roman naziva „romanom sećanja“ ili „romanom o sećanju“ inspirisan piščevom potrebom da „u sebi obnovi prošlost, ali ne u izbledelom sivilu fotografija iz porodičnog albuma, već u potpunosti, u tehnikoloru“. Međutim, vrativši se u svoj rodni Bombaj posle mnogo godina odsustva, Ruždi se suočio sa problemom koji pisci uglavnom imaju kada nastoje da pripovedaju o zemlji koju su odavno napustili:

[Ako] se osvrćemo unazad, to moramo da činimo sa znanjem - koje u nama budi duboku neizvesnost - da naša fizička otuđenost od Indije skoro neizbežno podrazumeva da je nemoguće da ponovo osvojimo potpuno istu izgubljenu stvar; ukratko, da ćemo stvoriti fikcije - ne stvarne gradove ili sela, već one nevidljive, te da će to biti naši imaginarni zavičaji, Indije kakve postoje samo u našim umovima. (Ruždi, 2007: 27)

Kroz pripovest nepouzdanog pripovedača Salima Sinaja, čiji lik je zamišljen kao svojevrsna alegorija Indije, Ruždi je u Deci ponoći stvorio upravo takvu verziju svoje rodne zemlje, sastavljenu od krhotina sećanja čije su pukotine ispunjene imaginacijom. Ovaj roman, objavljen 1981. godine, predstavlja jedan od najznačajnijih primera postmodernističkog preispitivanja istorijske istine, kroz čiju se složenost može sagledati proces rekonstruisanja prošlosti u kome se uvek ponešto dodaje, a nešto izostavlja. U ovom radu, usredsredićemo na sukob između pojedinačne, subjektivne verzije istorije koju pruža Ruždijev pripovedač Salim i formiranja zvaničnog istorijskog diskursa koji podleže brojnim političkim manipulacijama. Oslanjajući se na stav Milana Kundere da je „borba čoveka protiv moći borba čoveka protiv zaboravljanja“, Ruždi (2007: 30) i sâm ističe da je roman jedan od načina poricanja službene, političke verzije istine. Međutim, kako ćemo se truditi da istaknemo, to što se roman Deca ponoći suprotstavlja zvaničnoj verziji istorijske istine nikako ne znači da se u njemu individualna tačka gledišta nameće kao istorijski tačna. Naprotiv, oslanjajući se na teoriju Linde Hačion o žanru istoriografske metafikcije, nastojaćemo da prikažemo kako se, tokom čitanja ovog Ruždijevog romana, od čitaoca neprestano traži da preispituje verziju istorije o kojoj pripoveda Salim. Time se naglašava da svaki pokušaj oživljavanja prošlosti sadrži sopstvenu istinu, „istinu sećanja“, kako to Ruždijev pripovedač opisuje, ali i da se, bez obzira na to što svaka pojedinačna verzija poseduje sopstvenu vrednost, nijedna od njih ne može smatrati dominantnom ili važnijom od drugih.

U prvom delu rada, ukratko ćemo se osvrnuti na teorijsku misao o granicama između istorijskog i književnog diskursa koja igra važnu ulogu u formiranju postmodernog romana. Potom ćemo, u drugom delu rada, dati uvid u osnovne odlike istoriografske metafikcije, usredsređujući se na odnos između zvanične verzije istorijske istine i pojedinačnih perspektiva čija se važnost ističe u okvirima ovog žanra. U poslednjem, analitičkom delu rada, prikazaćemo na koji način se istorijska istina problematizuje u romanu Deca ponoći, posvećujući posebnu pažnju odnosu između 
njene zvanične verzije i individualne tačke gledišta koju nam pruža Ruždijev pripovedač Salim Sinaj, neraskidivo vezan za istoriju svoje zemlje od samog rođenja.

\section{Istorija i fikcija u diskursu postmoderne}

Granica između istorijskog i književnog diskursa predmet je brojnih razmatranja još od antičkih vremena. Kako u studiji o odnosu istorije i fikcije u romanima savremenog američkog pisca Dona DeLila ističe Vukotić (2018: 19), „istorija i književnost vekovima su posmatrane kao srodne discipline, a njihovo granično područje uglavnom je određivao odnos prema istini“. Pitanje da li se književnosti uopšte može pripisati kategorija istinitosti, na koje su pokušali da odgovore antički filozofi razvijajući na taj način više linija teorijskog mišljenja o istinitosti umetničkog dela, ostalo je, do dana današnjeg, jedno od najizazovnijih pitanja nauke o književnosti.

Premda su pitanja književne istine, kao i preispitivanja granica između istorijskog i književnog diskursa oduvek predstavljala neiscrpnu temu kojom su se podjednako bavili filozofi, istoričari, pisci i teoretičari književnosti, još od Aristotela koji je isticao prednost pesništva nad istoriografijom ${ }^{1}$, posebno interesovanje za ove teme donela je tek epoha postmoderne, pod uticajem lingvističkog obrta u filozofiji nakon koga je došlo do razvijanja velikog broja teorija koje su dovele do preispitivanja dotadašnjih temelja ljudskog znanja. Za razliku od tradicionalnog shvatanja istoriografije kao diskursa koji upućuje na stvarnost, što je vekovima predstavljalo distinktivnu odliku koja ga je razlikovala od književnog diskursa, lingvistički obrt u filozofiji, podstaknut Sosirovom idejom o arbitrarnosti jezičkog znaka, dovodi u pitanje postojanje bilo kakvih referenata van teksta (Vukotić, 2018: 35). Francuski strukturalizam doveo je do razvoja intertekstualnih teorija prema kojima se tekst ne odnosi ka stvarnosti, već uvek prema drugom tekstu. Ova ideja je u teorijskoj misli poststrukturalizma i dekonstrukcije rezultirala preispitivanjem stabilnog književnog značenja i istine književnosti dovodeći, u krajnjoj liniji do Deridinog stava da ne postoji ništa van teksta. Kada je u pitanju odnos fikcije ${ }^{2} \mathrm{i}$ istine, ove teorijske postavke doprinele su građenju „fikcije teksta“ koja je nezavisna od istine i stvarnosti, jer uvek ostaje u okvirima jezika (Kvas, 2011: 34). Pored toga, kako primećuje Julija Kristeva, koja je, oslanjajući se na ideje Mihaila Bahtina, skovala termin intertekstualnost, s obzirom na to da tekst uvek već postoji u mreži drugih tekstova iz kojih crpi značenja, književnost nikako ne može oslikavati samo jednu, monolitnu istinu (Kvas, 2011: 34). Na taj način, teorija intertekstualnosti, naročito po shvatanju Julije Kristeve, preispituje i ruši logiku istine jednog sistema i dopušta, preko pojmova dijalogičnosti i heteroglosije, da se u rečima neprestano smenjuju alternativna značenja (Kvas, 2011: 35).

Pomenuta razmišljanja koja su nastala pod uticajem francuskog strukturalizma izuzetno su značajna kada je u pitanju razmatranje postmodernističkog odnosa

1 Govoreći o granicama između pesništva i istoriografije, Aristotel (2008: 71-72) u delu 0 pesničkoj umetnosti ističe da je „pesništvo više filozofska i ozbiljnija stvar nego li istoriografija, jer pesništvo prikazuje više ono što je opšte, a istoriografija ono što je pojedinačno“.

2 U studiji Istina i poetika, Kvas (2011: 24-25) ističe da termin fikcija u razumevanje književnosti ulazi počev od XVI veka kao „imaginativna sposobnost stvaranja nestvarnog“. 
prema istoriji i fikciji, koje je rezultiralo popularizovanjem žanra koji je Hačion nazvala istoriografskom metafikcijom. Postmoderni roman, tako, počiva na svesti o tome da ne postoji jedna Istina, već samo istine u množini, kao i da nema neistine kao takve, već postoje samo tuđe istine (Hutcheon, 1988: 109). Na sličan način, romani koji se svrstavaju u žanr istoriografske metafikcije prikazuju da ne postoji jedna, objektivna istorija, već samo pojedinačne istorije. Međutim, relativizacija istorijskog znanja dovodi do, prema Hačion (Hutcheon, 1988: 87), pogrešnog stava da je postmoderna umetnost „aistorijska“, ili, u krajnjoj liniji, do potpunog poricanja mogućnosti spoznaje istorijske istine. Postmoderna, prema njenom mišljenju, ne pokušava da porekne da se prošlost dogodila, već samo ukazuje na to da nam je ona dostupna jedino posredstvom teksta.

Ključna razlika koja predstavlja temelj savremenih izučavanja odnosa između istorije i fikcije predstavlja ona između istorije kao niza sirovih empirijskih realiteta $i$ istorije kao procesa pisanja. Hačion (Hutcheon, 1988: 92) proces kritičkog preispitivanja i analiziranja zapisa iz prošlosti naziva istorijskim metodom, a proces imaginativne rekonstrukcije prošlosti jeste istoriografija. Na taj način, distinktivne odlike koje su do tada odvajale fikciju od istoriografije podrivaju se pod uticajem ideje da je u oba slučaja u pitanju diskurs, te da je posao istoričara vrlo sličan procesu stvaranja književnog dela. Posmatranje rada istoričara kao poetskog čina u najvećoj meri potiče od ideja koje je u studijama Metahistory: The Historical Imagination in Nineteenth-Century Europe i Tropics od Discours: Essays in Cultural Criticism izneo američki istoričar Hejden Vajt. Pod uticajem Ničeove kritike istoriografskog diskursa, kao i teorijskih postavki strukturalista i poststrukturalista, Vajt, prema rečima Markovskog (Markovski/Bužinjska, 2009: 554), „preokreće tradicionalan, realistički odnos između istorijske stvarnosti i pripovesti i dokazuje da naracija nije sekundarna u odnosu na svet, već primarna, i da ona određuje njegov smisao“. Ovo ipak ne znači da prošlost ne postoji, već da mi nemamo neposredan pristup do nje, te da joj možemo pristupiti jedino pomoću tekstova koji joj daju „pristrasan i često preokrenut" smisao (Markovski/Bužinjska, 2009: 555).

Kako ističe Vukotić (2018: 23), „rez“ koji je postmoderna napravila sa prethodnim teorijama, dovodeći do preispitivanja svih prethodno uspostavljenih vrednosti posebno je uočljiv u Vajtovoj kritici engleskog filozofa i istoričara Kolingvuda, koji je isticao da "neprerađene činjenice“ nemaju nikakvo značenje sve dok istoričar od njih ne napravi uverljivu priču. Vajt (White, 1986: 84), s druge strane, u studiji Tropics od Discourse: Essays in Cultural Criticism, ističe da se ni sami istorijski događaji ne mogu posmatrati kao činjenice, već isključivo kao „elementi priče“ koji se, u okviru istoriografije pretaču u uverljivu priču tehnikama kojima se oblikuje roman ili dramski komad, a to su potiskivanje ili naglašavanje određenih elemenata priče, karakterizacija, ponavljanje motiva, varijacije tona ili tačke gledišta, kao različite strategije opisivanja. Dakle, premda Kolingvud ističe ulogu istoričara u prerađivanju istorijskih činjenica, njihov ontološki status biće preispitan tek u epohi postmoderne, što će, u krajnjoj liniji, dovesti do ekstremnih stanovišta koja poriču samo postojanje istorijske istine. 
Premda se u okvirima žanra istoriografske metafikcije ne poriče ontološki status prošlosti, na postmoderni roman u velikoj meri su uticale i teorijske postavke $\mathrm{u}$ kojima se pojam istorijske istine relativizuje do krajnjih granica. Čuvena studija Žana Bodrijara, Zalivski rat se nije dogodio (1991), ukazuje na to do koje mere percepcija istorijskih događaja može biti podložna manipulacijama, te da se pod različitim uticajima može poljuljati čak i njihov ontološki status. Kako primećuje Vukotić (2018: 38), iako Bodrijarovo stanovište predstavlja radikalno poricanje mogućnosti spoznaje istorijskog znanja koje Hačion (Hutcheon, 1991: 33) naziva „apokaliptičkim nihilizmom", ne može se poreći značaj koji ova teorija ima, makar kao metaforička slika savremenog društva $u$ kome je istina u velikoj meri oblikovana ideologijom i posredovana medijima. Ideja o tome da se prošlost nije dogodila zapravo je „metafora sveta u kome događaji počinju da se posmatraju kao materijal za scenario koji može imati mnoštvo različitih funkcija“" (Vukotić, 2018: 38). Iako se, prema Hačion, u postmodernističkoj prozi ne poriče ontološki status prošlosti, mnogi autori se makar ironično poigravaju idejama koje je definisao Bodrijar, ističući da je stvarnost vrlo često do te mere fabrikovana da pojedinac ponekad ne može da se osloni ni na sopstveno iskustvo. To je uočljivo u Ruždijevom romanu Deca ponoći, naročito kada glavni junak, Salim Sinaj, tokom indijsko-pakistanskog rata koji mu je promenio život iz korena, više nije u stanju da razluči šta je stvarnost, a šta iluzija, pitajući se da li su se užasi tog rata zaista odigrali:

Kome verovati? Da li su pakistanski lovci-bombarderi stvarno izvršili „smeli prepad“ i iznenadili trećinu bespomoćnog indijskog ratnog vazduhoplovstva na pistama? Jesu li ili nisu? I oni noćni balovi na nebu, pakistanski „miraži“ $i$ „misteri“ protiv indijskih "migova“ - sa nešto manje romantičnim nazivom: da li su islamska priviđenja i misterije vodile bitku sa indijskim osvajačima, ili je sve to bila samo nekakva neverovatna iluzija? Jesu li bombe padale? Je li doista bilo eksplozija? Zar čak i smrt može biti problematična? (Ruždi, 2019: 425)

Ruždijev roman, kako ćemo pokazati u analitičkom delu rada, predstavlja odličan primer istraživanja granica između istorijske istine i fikcije, neprestano preispitujući način na koji pojedinac pokušava da spozna istoriju sopstvene zemlje. Ipak, najpre ćemo ukratko definisati osnovne odlike žanra istoriografske metafikcije koje je definisala Hačion, kako bismo potom dublje istražili odnos između zvanične i individualne istorije u ovom romanu.

\section{Zvanično $i$ individualno $u$ diskursu istoriografske metafikcije}

Žanr istoriografske metafikcije nastao je kao rezultat sve većeg interesovanja za brojne sličnosti koje su uočene između diskursa istorije i književnosti kao fikcije. Kako ističe Hačion (Hutcheon, 1988: 88), provizorna, neodređena priroda istorijskog znanja nije otkriće postmodernizma, kao ni preispitivanje ontološkog i epistemološkog statusa istorijskih činjenica, ali se usredsređenost na ove probleme u epohi 
postmoderne ne može ignorisati. Usredsređenost na te probleme dovela je, prema Hačion (Hutcheon, 1988: 93) do stvaranja novog žanra koji opovrgava prirodne i zdravorazumske metode razdvajanja istorijske činjenice i fikcije, te odbacujući stanovište da samo istorija sadrži kriterijum istine, istoriju i fikciju svodi na nivo diskursa koji je, u oba slučaja, ljudski konstrukt. Nadalje, ova teoretičarka ističe da oba „žanra“3 neizbežno stvaraju konstrukt tako što tekstualizuju prošlost, pokazujući da je pravi referent njihovog jezika nekada postojao, ali mu se danas može pristupiti samo posredstvom teksta (Hutcheon, 1988: 93). Tako nas istoriografska metafikcija samosvesno podseća da, premda su se događaju odigrali u stvarnoj, empirijskoj prošlosti, mi imenujemo te događaje kao istorijske činjenice procesom selekcije $i$ narativnog postavljanja (1988: 97).

Dakle, prema Hačion (Hutcheon, 1988: 92) postmoderna, osim u svojim ekstremnijim oblicima ${ }^{4}$, ne poriče postojanje istorijske istine, ali se u postmodernističkom ispisivanju istorije podrivaju osnovne pretpostavke na kojima počivaju istorijski iskazi: objektivnost, neutralnost, impersonalnost i prozirnost prikazivanja. Izuzetno važan segment istoriografske metafikcije, naročito kada je u pitanju roman Deca ponoći Salmana Ruždija, jeste isticanje da se ne može govoriti o jednoj, objektivnoj istini, već uvek o istinama u množini. Ovo se posebno da uočiti kada se uzme u obzir razlika između osobina glavnih junaka postmoderne fikcije i istorijskih romana iz devetnaestog veka. Oslanjajući se na definiciju istorijskog romana Đerđa Lukača, Hačion (Hutcheon, 1988: 113) ističe da on predstavlja istorijski proces prikazujući "mikrokosmos koji uopštava i koncentriše“, te je tako protagonista ovog romana uglavnom određeni tip, sinteza opšteg i pojedinačnog. $S$ druge strane, protagonisti postmodernog romana su sušta suprotnost tome - oni su „eks-centrici, marginalizovane i periferne figure fikcionalne istorije", a odličan primer toga predstavlja, kako ćemo nadalje prikazati, Ruždijev Salim Sinaj (Hutcheon, 1988: 113-114). Tako istoriografska metafikcija, posredstvom decentralizacije, rasvetljava pojedinačne istine koje jedna drugu ne potiskuju, već su sve podjednako relevantne u sagledavanju istorijske istine. U eseju „Imaginarni zavičaji“, Salman Ruždi ističe da je Decu ponoći napisao motivisan željom da sagleda istoriju zemlje u kojoj se rodio, ali da mu je, kao i svim piscima koji su emigrirali iz Indije, bilo teško da sagleda kako njenu sadašnjost, tako i prošlost, jer se u sadašnjosti susreo sa potpuno drugačijom zemljom od one u kojoj je odrastao, dok su ga ka prošlosti vodila samo nepouzdana sećanja. Tako je shvatio da je ono što piše zapravo „roman sećanja“ i roman „o sećanju“, te da je „njegova“ Indija baš to - njegova Indija, „samo jedna verzija od hiljada miliona mogućih“ (Ruždi, 2007: 28). Stoga je učinio da njegov nepouzdani pripovedač Salim neprestano preispituje koncept istorijske istine sumnjajući u istinitost sopstvene pripovesti, ponekad čak i pogrešno predstavljajući istorijske činjenice, svestan da su greške rezultat varljivog sećanja. Međutim, to ne čini njegovu verziju istine ništa

3 U studiji Don DeLilo i poetika istorije, Vukotić (2018: 49) primećuje da Hačion, bez obzira na to što se svrstava u „umerenije struje“ kad je u pitanju poređenje istorije i fikcije, te istoriju ne posmatra kao apsolutnu konstrukciju, istoriju i fikciju ipak naziva „žanrovima“, što nije adekvatan termin za obe discipline.

4 U pitanju je, recimo, pomenuta teorija Žana Bodrijara. 
manje relevantnom, i to je jedan od ključnih elemenata postmodernističkog preispitivanja istorijske istine. Kako Ruždi (2007: 28) zaključuje, svaki pisac iz Indije koji o njoj piše iz pozicije emigranta primoran je da se suoči sa „slomljenim ogledalom“ čiji su delovi nepovratno izgubljeni, ali to slomljeno ogledalo, paradoksalno, može biti jednako vredno kao i ono koje je netaknuto.

Metafora sa slomljenim ogledalom, koju opisuje Ruždi, na odličan način prikazuje poziciju subjekta u okviru istoriografske metafikcije. U ovom žanru, prema Hačion (Hutcheon, 1988: 117), dominantna su dva načina pripovedanja, od kojih oba problematizuju pojam subjektivnosti. To su uključivanje više tačaka gledišta $i$ uvođenje otvoreno kontrolisanog pripovedača. Ni u jednom od njih, kako ističe ova teoretičarka, ne možemo pronaći subjekta koji bi bio uveren u sopstvenu sposobnost da sa bilo kakvom sigurnošću spozna prošlost. To, međutim, kako upozorava, nije "prevazilaženje istorije“, već „problematizovano upisivanje subjektivnosti u istoriju“ (Hutcheon, 1988: 117-118). Na taj način, književnost postmoderne odbacuje takozvane „velike narative“ koji počivaju na iluziji objektivnosti, otvarajući mogućnost sagledavanja više različitih verzija istine istovremeno. Ideja o „višeglasju i višestrukosti istine" u savremenom romanu iskazuje se, kako zaključuje Vukotić (2018: 49), kroz mnoštvo različitih perspektiva koje jedna drugu poništavaju, ukazujući na neodrživost i neistinitost velikih priča koje pretenduju na bilo kakvu konačnost, odnosno mogućnost predstavljanja jedinstvene istine.

Odbacujući koncept velikih narativa, pisci istoriografske metafikcije neprestano preispituju odnos ličnog iskustva i javne svesti o istoriji. U tom pogledu, Hačion (Hutcheon, 1988: 94) ističe da "uzdići privatno iskustvo do javne svesti“ ne znači proširiti ono što je subjektivno, već pokazati da su javno i istorijsko, privatno i biografsko međusobno neodvojivi. Ovde navodi primer Dece ponoći, gde glavni junak i pripovedač, Salim Sinaj, sebe smatra odgovornim za istorijske događaje koji su povezani sa njegovim životom. Na ovaj način, kako ističe, u ovom delu je prisutno otvoreno razmišljanje o istorijskom premeštanju i njegovim ideološkim posledicama, o načinu na kojoj se piše o prošloj stvarnosti, o onome što sačinjava poznate činjenice bilo kog datog događaja (Hutcheon, 1988: 94). Stoga je jedna od velikih tema Ruždijevog romana, kao i istoriografske metafikcije uopšte, odnos između zvanične i individualne istorije. U eseju „Imaginarni zavičaji“, Ruždi (2007: 30) ističe ulogu koju ima pisac „u vremenima kada Država uzima stvarnost u svoje ruke i pokušava da je izobliči, prilagođavajući prošlost potrebama sadašnjosti“. Stoga pisce i političare Ruždi posmatra kao „prirodne suparnike“ (2007: 30), jer i jedni i drugi pokušavaju da oblikuju svet prema sopstvenim merilima. Tako roman za njega predstavlja jedan od načina opovrgavanja zvanične, politizovane verzije istine.

Postmoderni roman, prema Hačion (Hutcheon, 1988: 179), ponovo spaja ideološko i estetsko, što predstavlja odvajanje od romantičarskog i modernističkog nasleđa koje ističe da u književnom delu nema mesta za ideološki diskurs, kao i stava da je umetnost trivijalna, izmaštana, i stoga izdvojena od društvene i političke realnosti. Stoga, potvrđujući stav Terija Igltona, Hačion (Hutcheon, 1988: 178) zaključuje da nas postmoderna teorija i praksa ne uče toliko tome da je istina iluzorna, 
koliko tome da je ona institucionalna, jer jezik uvek koristimo u kontekstu političkodiskurzivnih okolnosti. Nadalje, postmodernistička umetnost i teorija samosvesno su prihvatile svoje ideološko postavljanje u svetu, ne samo u cilju reagovanja na provokativne optužbe o trivijalnosti umetnosti, već i u cilju davanja glasa „eks-centricima“, pojedincima koji izlaze iz okvira monolitne zapadnjačke kulture, onima koje je marginalizacija naučila tome da umetnici uvek moraju imati sebi svojstven politički status (Hutcheon, 1988: 179). Ipak, kako Hačion (Hutcheon, 1988: 180) upozorava, istoriografske metafikcije nisu ideološki romani, jer oni ne pokušavaju da, putem fikcije, ubede svoje čitaoce $u$ tačnost $i$ istinitost jednog načina tumačenja sveta. Naprotiv, inkorporirajući alternativne verzije istine koje se suprotstavljaju zvaničnoj, romani istoriografske metafikcije čitaoce nagone da preispituju sopstvena tumačenja.

\section{Deca ponoći}

Ruždijev roman Deca ponoći, objavljen 1981. godine, predstavlja izvrstan primer žanra istoriografske metafikcije, jer se u njegovim okvirima preispituju gotova sva relevantna pitanja vezana za pokušaj spoznaje istorijske istine. Život Ruždijevog glavnog junaka Salima Sinaja, koji je rođen u istom času kada je Indija dobila nezavisnost, predstavlja, prema mišljenju mnogih kritičara, pravu alegorijsku sliku njegove rodne zemlje - od sticanja nezavisnosti, preko rata sa Pakistanom koji je doveo do razdvajanja, pa sve do formiranja Bangladeša i vladavine Indire Gandi. Sama struktura romana podeljena je u tri celine. Prvi deo pokriva istoriju Salimove porodice od 1915. do njegovog rođenja 1947. Druga celina romana počinje Salimovim rođenjem u času proglašenja nezavisnosti Indije, zajedno sa još hiljadu druge dece obdarene različitim natprirodnim moćima, te obuhvata period njegovog detinjstva i adolescencije sve do 1965. godine kada gotovo cela njegova porodica strada $u$ indijsko-pakistanskom ratu. Treći deo pokriva vremenski period od 1970. do 1978. godine, tokom koje se Salim, nakon što je u ratu pretrpeo snažan udarac u glavu i izgubio pamćenje, nalazi u središtu novog sukoba, između istočnog i zapadnog Pakistana. Ovaj period obeležilo je formiranje države Bangladeš, a potom i proglašenje vanrednog stanja u Indiji tokom vladavine Indire Gandi. Povezana sa svim ovim događajima, životna priča Salima Sinaja od samog početka nerazdvojna je od istorije Indije, što se naglašava od samog trenutka njegovog rođenja. Kao jedno od „dece ponoći“, Salim je od ranog detinjstva osećao teret istorije, jer je njegov život, kao i istorija nezavisne Indije, od obećavajućeg početka punog nade u bolju budućnost na kraju bio ispunjen brojnim sukobima i stradanjima. Pokušavajući da se uhvati u koštac sa događajima koji su mu odredili životni put, Salim pripoveda, kako je Ruždi naglašavao, svoju verziju istorije, koja je oslobođena pretenzija na objektivnost, ali istovremeno predstavlja i ono što je Hačion (Hutcheon, 1988: 118) nazvala „problematizovanim upisivanjem subjektivnosti u istoriju“.

Salim Sinaj, kao nepouzdani pripovedač kroz čiju prizmu posmatramo kako događaje nakon njegovog rođenja, tako i one koji su mu prethodili, uspostavlja vlastiti odnos prema istorijskoj istini, koji čitalac mora neprestano da preispituje. Tako ovaj 
roman predstavlja primer destabilizacije subjekta, koja dalje vodi ka destabilizaciji samog narativa i same istorije. Prema Hačion (Hutcheon, 1988: 160), postmodernizam uspostavlja, diferencira, a zatim ruši stabilne narativne glasove, koji koriste pamćenje kako bi pokušali da prošlost daju smisao. Tako se u diskursu istoriografske metafikcije podriva stabilna tačka gledišta koja je u modernističkom romanu garantovala subjektivnost. To se čini na dva načina - uvođenjem pripovedača koji namerno manipuliše istorijskim događajima, ili uvođenjem mnoštva glasova umesto jedne, dominantne perspektive. Ova dva tipa metafikcionalne naracije često su, kako primećuje Hačion (Hutcheon, 1988: 161), prisutna istovremeno, te se, kao u slučaju Dece ponoći, pojedinačnost i mnogostrukost spajaju. Uprkos tome što postoji jedinstven, dominantan pripovedač koji kontroliše diskurs - pisac koji zna da istovremeno izveštava i stvara javnu i privatnu verziju istorije - (muški) centar ovog romana neprestano se izmešta i rasipa, a potraga za jedinstvom (narativa, istorije i subjekta) neprestano se osujećuje (Hutcheon, 1988: 161). Destabilizacija subjekta kao nedeljivog jedinstva posebno je uočljivo u Salimovom isticanju da on predstavlja mnoštvo stvari koje su mu prethodile i koje će doći posle njega:

Ko sam - šta sam? Odgovaram: ja sam celokupni zbir svega što mi je prethodilo, svega onoga što sam bio video učinio, svega što su mi učinili. Ja sam sve što je na mene u životu uticalo, sve na šta sam uticao. Ja sam sve ono što će biti kad mene više ne bude, a čega ne bi bilo da mene nije bilo. A nisam baš neki izuzetak u tom pogledu; svako „ja“, sve i jedan od nas šest stotina miliona sadrži slično mnoštvo. Poslednji put ponavljam: da biste mene razumeli, morate progutati ceo svet. (Ruždi, 2019: 476)

Destabilizacija subjekta u istoriografskoj metafikciji, a i u ovom romanu konkretno, prema Hačion rezultira destabilizacijom narativa, koji se opire svakom pokušaju uspostavljanja reda i linearnosti. Tako se Salim neprestano opire linearnom pripovedanju, iako mu njegova slušateljka Padma, zahvaljujući kojoj pripovest dobija oblik usmenog predanja, stalno sugeriše da joj događaje ispripoveda redom kojim su se odigrali. Nelinearno pripovedanje može se posmatrati kao jedan od brojnih načina suprotstavljanja klasičnom, zvaničnom prikazu istorijskih događaja. U članku „Teme i strukture u Deci ponoći“ Gurna (Gurnah, 2007: 97) ovo posmatra kao potrebu da se pripovedač oslobodi stega koje nameće zvanični diskurs, te ističe da bi, u ovim okolnostima, linearno pripovedanje „lagalo“. Ono bi „nametalo red tamo gde vlada nered, jednostavno značenje tamo gde su mogući samo kompleksni fragmenti“ (Gurnah, 2007: 97). Stoga je linearno pripovedanje zvanično, dok nelinearnu strukturu teksta karakteriše ono što je Bahtin nazvao heteroglosijom, mnoštvo glasova i značenja koji se međusobno ne isključuju, već zajedno učestvuju u beskrajnoj igri (Gurnah, 2007: 97).

Shvatajući Indiju kao „novi mit“, odnosno kao „kolektivnu fikciju u kojoj je sve moguće" (Ruždi, 2019: 140), Salim se slobodno poigrava procesom pisanja sopstvene verzije istorije, što se može sagledati na više načina. S jedne strane, to je svojevrsno 
parodiranje procesa stvaranja istorije u kome se odbacuje mogućnost postojanja referenta u stvarnosti i prilikom koga pisac ima slobodu da događaje uobliči po sopstvenoj volji. S druge, ipak, kao što ćemo videti, Salimova pripovest predstavlja izuzetno snažnu pojedinačnu perspektivu koja se sukobljava sa zvaničnim diskursom, nastojeći da otkrije ono što je u okviru njega izokrenuto ili potisnuto. Tako se u romanu Deca ponoći neprestano naglašavaju i sukobljavaju dva ključna elementa oživljavanja istorije koja čitaoca nagone na dalje preispitivanje. To je, na prvom mestu, svest da svako oživljavanje istorije kroz tekst sa sobom nosi mogućnost izokretanja istorijskih činjenica koje, u krajnjoj liniji, može dovesti u pitanje čak i njihov ontološki status. Ipak, kroz Salimovu pripovest neprestano se ističe i važnost pojedinačnih perspektiva marginalizovanih glasova, u čijim se verzijama može doći do dublje spoznaje istorijske istine u odnosu na njenu zvaničnu verziju. Na taj način, Ruždi potvrđuje svoj stav da se, pisac koji nastoji da prikaže istoriju svoje zemlje suočava sa „slomljenim ogledalom“, ali da to ogledalo može biti jednako vredno, ako ne i vrednije od celog.

Jedan od načina na koji se ističe da roman Deca ponoći ne predstavlja pokušaj da se objektivno sagleda istorija Indije, već da je u pitanju jedna od njenih brojnih verzija, jeste namerno isticanje da Salimova pripovest sadrži dosta grešaka kada su u pitanju lako proverljive istorijske činjenice. Tako recimo Salim sam ističe da je pogrešio datum ubistva Mahatme Gandija:

Iščitavajući ponovo svoje delo, otkrivam jednu grešku u hronologiji. Ubistvo Mahatme Gandija događa se, na ovim stranicama, pogrešnog datuma. Ali ne mogu sada da kažem kakav je možda bio stvarni redosled događaja; u mojoj Indiji Gandi će i dalje umirati u pogrešno vreme. (Ruždi, 2019: 210)

Na taj način, sa izvesnom dozom ironije, Ruždi preispituje savremene teorije koje dovode u pitanje status istorijske istine tvrdeći da se ona ostvaruje tek u obliku teksta. Tako Salim u jednom momentu zaključuje da je „u autobiografiji, kao i u celokupnoj književnosti, ono što se zaista dogodilo manje značajno od onog u šta pisac može ubediti svoje čitaoce da poveruju..." (Ruždi, 2019: 339). Ovo ne čini samo kada su u pitanju istorijske ličnosti, već i kada govori o onim izmaštanim. Ne znajući šta se dogodilo sa njegovim rivalom Šivom, detetom ponoći koje se rodilo u istom trenutku kad i on i koje je s njim zamenjeno na rođenju, Salim izmišlja da je on ubijen, ali ubrzo čitaocima priznaje da je u pitanju neistina:

[Prvi] put bio sam žrtva iskušenja znanog svakog autobiografu, žrtva iluzije da se - pošto prošlost postoji samo u sećanjima i rečima koje uzalud nastoje da ih obuhvate - mogu stvarati prošli događaji pukim kazivanjem da su se oni odigrali. (Ruždi, 2019: 547)

Stoga možemo zaključiti se ovde na izvestan način parodiraju teorijske postavke prema kojima se istorijska istina ostvaruje isključivo u tekstu. Pored toga, Salimovo prilagođavanje istorijskih događaja sopstvenom narativu može se posmatra- 
ti kao ironični prikaz autoriteta koji, prema Ruždijevim rečima, „menjaju prošlost kako bi je prilagodili sadašnjim potrebama“, stvarajući zvaničnu verziju istorije koja odgovara datoj ideologiji. Ovim se, dakle, upućuje na ulogu retorike u pisanju istorije, čime se prikazuje da istorija više počiva na tome kako i kojim redom su stvari prikazane, nego na njihovoj istinitosti (Dhar, 1993: 102). Tako se, u ovom romanu, neprestano parodira proces stvaranja zvaničnog diskursa, sa ciljem da se on odbaci, kako bi na njegovo mesto došlo mnoštvo različitih verzija istine koje treba neprestano preispitivati. Time se otvara prostor za potisnute, marginalizovane perspektive, za koje nema mesta u strogim okvirima zvanične kulture.

Salimova verzija istorije Indije i Pakistana neprestano se, dakle, sukobljava sa zvaničnom, što se postiže svojevrsnim parodiranjem formiranja zvaničnog diskursa. Iz tog razloga su, između ostalog, pojedini čitaoci Ruždiju zamerali činjenicu da roman sadrži dosta grešaka. Kako u eseju o nepouzdanom pripovedanju u Deci ponoći ističe sam Ruždi (Rushdie, 2010: 25), ovi čitaoci su, ne prepoznajući sloj ironije, Decu ponoći doživeli kao istorijsku knjigu, ili čak udžbenik, što ona nikad nije pretendovala da bude. Kako dalje navodi, Salimova priča nije istorija, ali se poigrava sa istorijskim oblicima. Stoga je ona izrazit primer istoriografske metafikcije, jer čitaoca neprestano podstiče na preispitivanje, postavljajući u centar pojedinca koji na osnovu varljivih sećanja nastoji da formira sopstvenu verziju istine. U pitanju je, dakle, ono što Salim u jednom trenutku svoje pripovesti naziva „istinom pamćenja“:

Sve što sam vam kazao sušta je istina“, ponavljam, „istina pamćenja, jer pamćenje ima svoju istinu. Ono odabira, izostavlja, menja, preteruje, omalovažava, glorifikuje, a i nipodaštava: ali na kraju ono stvara sopstvenu stvarnost, svoju raznorodnu ali obično povezanu verziju događaja; i niko pametan ne veruje tuđoj verziji više nego svojoj. (Ruždi, 2019: 264-265)

Nadalje, ono što se, u Deci ponoći, može uočiti kao suštinska razlika između formiranja zvanične istorije i pojedinačnih verzija istorijske istine, jeste činjenica da Salim nije nepristrasni posmatrač ili hroničar koji događaje posmatra sa distance (Rushdie, 2010: 24). Ti događaji su oblikovali njegov život, te je i on primoran da pokuša njih da oblikuje na osnovu sećanja i da im time da smisao. Salim je, dakle, za razliku od autoriteta koji obliku stvarnost prema sopstvenim merilima, podstaknut sasvim drugačijim pobudama. On sopstvenu verziju istorije formira kako bi na taj način uspeo da razume makar jedan deo svih događaja koji su odredili njegov životni put. Iako je do istine sve teže doći, jer ona podleže sve većim manipulacijama, Salim nastoji da makar pokuša da razume stvarnost u kojoj živi:

U zemlji u kojoj je istina ono što joj se kaže da bude, stvarnost sasvim doslovno prestaje da postoji, tako da sve postaje moguće, osim ono što nam se tvrdi da jeste; a možda u tome leži razlika između mog detinjstva u Indiji i adolescencije u Pakistanu - u Indiji su me sa svih strana opsedale beskraj- 
ne alternativne stvarnosti, dok sam u Pakistanu plutao, dezorijentisan, na isto tako beskrajnom moru laži, nestvarnosti i neistina. (Ruždi, 2019: 408)

Tako je Salimova pripovest, prema Ruždijevim rečima, konstruisana tako da se u njegovom nepouzdanom pripovedanju pronađe analogija sa načinom na koji svaki pojedinac, svakodnevno, pokušava da tumači svet oko sebe:

Istorija je uvek dvosmislena. Činjenice se teško uspostavljaju i može im se pripisati mnogo različitih značenja. Stvarnost je izgrađena od naših predrasuda, pogrešnih shvatanja i neznanja, koliko i od našeg znanja i moći zapažanja. Čitanje Salimovog nepouzdanog pripovedanja, moglo bi biti, smatrao sam, korisna analogija za način na koji svi mi, svakog dana, pokušavamo da "pročitamo“" svet. ${ }^{5}$ (Rushdie, 2010: 25)

Pored toga što daje uvid u način na koji svaki pojedinac pokušava da dopre do istine i smisla, Salimova pripovest, ispod površinskog dela koji je obojen ironijom, predstavlja vrlo snažan prikaz nepovoljnog položaja koji taj pojedinac ima unutar istorijskog konteksta na koji je osuđen od rođenja. Tako se Salimovo ponovno proživljavanje bolne istorije kroz pripovedanje odražava čak i na njegovom telu, koje se lagano raspada pod teretom istorije:

Iako sada, kad je sve što je bilo u meni već gotovo iscurilo; dok pukotine u meni sve šire zjape - čujem i osećam prštanje, paranje, krckanje - tanjim se i postajem gotovo prozračan, nije mnogo od mene ostalo, a uskoro neće baš ništa preostati. Šeststo miliona trunki prašune, a svaka prozračna, nevidljiva kao staklo. (Ruždi, 2019: 476)

Stoga se ne možemo do kraja složiti sa tvrdnjom pojedinih kritičara da Salim „uopšte nije književni lik u pravom smislu te reči, već samo otelovljenje istorije, ništa više od glasa" (Dhar, 1993: 96). On svakako jeste, na izvestan način, alegorijski prikaz Indije, ali se kroz njegov lik istovremeno može sagledati pozicija pojedinca koji postaje žrtva istorije. Premda u Salimovom povezivanju istorijskih događaja sa sopstvenim životom ima dosta ironije, jer on sebe doživljava kao centralnu figuru koja je odgovorna za sva dešavanja, te se pojedina povezivanja graniče sa apsurdom, kroz njegovu perspektivu sagledavamo istoriju „iznutra“, iz ugla pojedinca koji je bio svedok mnogih događaja i kome je rat odneo čitavu porodicu. Kako ističe Gurna (Gurnah, 2007: 104), ima nečeg pomalo komičnog i zabavnog u Salimovoj opsednutosti sopstvenom centralnošću i to je posebno uočljivo kada se zapita zašto baš on, od više od pet stotina miliona Indijaca, mora da nosi teret istorije. Postavljajući sebe u centar zbivanja, Salim događaje iz svog života neprestano povezuje sa onim istorijskim, te je tako ubeđen da je potajni cilj indijsko-pakistanskog rata bio da se

5 Svi navodi strane literature dati su u mom prevodu. 
njegova porodica zbriše sa lica zemlje, a da je cilj uvođenja vanrednog stanja bio da se unište deca ponoći. Ipak, može se reći da je, kroz Salimovu zabludu, prikazano da se, suprotno zvaničnom diskursu koji počiva na jednom strogo utvrđenom ideološkom centru, svaka pojedinačna perspektiva može posmatrati kao centralna, te da svaka od njih u sebi sadrži sopstvenu istinu.

Kao marginalizovani glas za koji nema mesta u zvaničnoj verziji istorije, Salim se često sukobljava sa autoritetima koji nastoje da istoriju oblikuju prema svojim merilima, poričući da su se pojedini događaji uopšte odigrali. To je posebno uočljivo u trećem delu romana kada ga, nakon što u indijsko-pakistanskom ratu gubi pamćenje, zbog izraženog čula mirisa koriste kao psa tragača tokom sukoba između istočnog i zapadnog Pakistana. Logor u kome je Salim bio u zvaničnoj verziji istorije ne postoji, te se o njemu nešto može saznati samo iz pojedinačnih pripovesti kao što je njegova:

Logor u brdima nećete pronaći ni u jednoj geografskoj karti (...) Žičana ograda izvrsno je kamuflirana; na kapiji nema nikakvog znaka ili naziva. A logor ipak postoji, postojao je; premda su njegovo postojanje vatreno poricali - ne primer, prilikom pada Dake, kada je poraženog pakistanskog Tigra Nijazija saslušavao u ovom pitanju njegov stari prijatelj, pobedonosni indijski general Sem Manekšo, Tigar se podsmehnuo: „Kerovi za ekstraobaveštajne razaračke aktivnosti? Nikad nisam čuo za takve jedinice. Neko te je nasamario, stari moj. Dovraga, baš smešna ideja, da prostiš." Uprkos tome što je Tigar rekao Semu, ja tvrdim: logor je sigurno postojao... (Ruždi, 2019: 433)

Premda je Salimova verzija istorijske istine nepouzdana i čitalac je primoran da je stalno preispituje, ovaj primer pokazuje u kojoj meri zvanična verzija istorije može biti oblikovana različitim manipulacijama, te tako ona pojedinačna, premda počiva na nepouzdanom sećanju, postaje mnogo ubedljivija. Kroz ovaj primer ističe se, na taj način, česta praksa da se sramni istorijski događaji potisnu u drugi plan tako što će dovoljno puta biti ponovljeno da se uopšte nisu odigrali:

Kao da neki oblačić minu licem generala Sema: „Slušaj, stari druže, danas se laže na svakom koraku. Pokolji, stari moj, masovne grobnice, specijalne jedinice zvane KERA i kojekakve koještarije, formirane radi toga da se uništi opozicija...Nema valjda u tome trunke istine?“ A Tigar će: „Kerovi za ekstraobaveštajne i razaračke aktivnosti? Prvi put čujem. Mora da su te zaveli na pogrešan put, stari moj.“ (Ruždi, 2019: 472)

Našavši se u središtu događaja o kojima se izveštava na mnogo različitih načina koji jedan drugom protivreče, Salim više nije u stanju da se osloni ni na sopstvena čula. To se može uočiti u već pomenutom pasusu u kome se on pita da li su bombe zaista padale i da li je bilo eksplozija u kojoj je poginuo veliki broj ljudi. Pored toga, perspektiva pojedinca koji proživljava užase rata takođe je obeležena nevericom da 
je to što se dešava zaista moguće. Tako Salim, premda događaje posmatra sopstvenim očima, ne može da poveruje da su oni istiniti:

I tako sam se vratio u taj grad, u kome smo, u poslednjim časovima uoči susreta starih znanaca, Šahid i ja videli koješta što nije bila istina, što nije bilo moguće, jer se naši momci nisu mogli, ni kad bi hteli, ponašati tako ogavno; videli smo kako ljude sa jajastim glavama streljaju po sokacima; videli smo kako naveliko kasape gradsku inteligenciju, ali nije bilo istina, jer nije mogla biti istina...(Ruždi, 2019: 467)

Salimova verzija istorije, na taj način, prestavlja pokušaj svakog pojedinca da pojmi svet oko sebe i da se uhvati u koštac sa istinom, koliko god tragična i teška ona bila. Vezan za istoriju, kako sam kaže, „aktivno-doslovno, pasivno-metaforično, aktivno-metaforično i pasivno-doslovno“ i "nerazmrsivo spleten sa svojim svetom“ (Ruždi, 2019: 297-298), Salim pripoveda iz potrebe da razume istoriju tog sveta, te da svoju priču ostavi kao svedočanstvo budućim pokolenjima. Odlična metafora kojom Ruždi, na kraju romana, predstavlja pokušaj da se sačuva prošlost jeste ona sa stavljanjem povrća i voća u turšiju. Spajajući banalno sa uzvišenim, Ruždi ovom metaforom savršeno prikazuje kako svaki pokušaj da sačuvamo sećanje na prošle događaje neminovno podleže promenama - ponešto se dodaje, ponešto oduzima, ukus se vremenom menja, kao što se menja i naša percepcija tih događaja. Ispod slojeva ironije i slobodnog poigravanja sa tehnikama ispisivanja istorije, u romanu Deca ponoći ističe se izuzetna važnost pojedinačnih perspektiva koje, premda moraju biti podvrgnute stalnom preispitivanju, poseduju, prema Salimovim rečima, „autentičan ukus istine“:

Možda će svet jednoga dana okusiti turšije istorije. One će možda biti preoštre za neka nepca, možda će im miris biti prejak, možda će naterati suze na oči; a ipak se nadam da će se moći kazati da poseduju autentičan ukus istine...da je svaka od njih, uprkos svemu, čin ljubavi. (Ruždi, 2019: 568)

\section{Zaključak}

Na osnovu nekoliko odabranih primera koji čine osnovu ove kratke analize, mogli smo da uočimo kako se, u Deci ponoći, vrlo vešto prikazuje složenost ponovnog oživljavanja prošlosti. Kroz Salimovu pripovest Ruždi se slobodno poigrava sa granicama između istorije i fikcije, te sa teorijama koje ih poistovećuju naglašavajući da se istorijska istina formira tek u tekstu. Na taj način, ističe se kako se njome može lako manipulisati, što ima za rezultat potpuno izokretanje činjenica, kao i izbacivanje postojećih događaja ili izmišljanje nepostojećih. Stoga se, u žanru istoriografske metafikcije kome pripada ovaj roman, odbacuje svaka mogućnost stvaranja jedinstvene verzije događaja, te je moguće govoriti samo o pojedinačnim verzijama istorije, zasnovanim na različitim istinama. U ovom pogledu, roman Deca ponoći predstavlja odličan primer istoriografske metafikcije, jer se u njemu Salimova ver- 
zija ne nameće kao jedini ispravan način tumačenja sveta. Naprotiv, on predstavlja ono što je Ruždi nazvao „istinom pamćenja“, koju čitalac stalno mora da preispituje.

Postavljajući u centar marginalizovani glas koji pripoveda svoju verziju istine, kao što je prikazano, Salman Ruždi gradi vrlo kompleksan narativ kroz koji se može sagledati odnos između zvanične, politizovane verzije istorijske istine i perspektive pojedinca koji nastoji da sagleda događaje koji su mu oblikovali život. Perspektiva pojedinca, kako prikazuje Ruždi, zasnovana je na varljivom sećanju, te počiva na neminovnom dodavanju i izostavljanju podataka. Međutim, u odnosu na zvaničnu verziju istorije koja počiva na namernim političkim i ideološkim manipulacijama, istorija koju ispisuje pojedinac poput Salima inspirisana je snažnom potrebom da se sagleda sopstvena prošlost, te je, iako jednako nepouzdana, inspirisana plemenitim pobudama, što se posebno uočava u Salimovoj potrebi da svoju verziju istorije kao „ॅ̌in ljubavi“ ostavi svom potomstvu (Ruždi, 2019: 568). Tako se u Deci ponoći ističe izuzetan značaj pojedinačnih perspektiva u kojima se, bez obzira što moraju biti podvrgnute stalnom preispitivanju, bar u određenoj meri razotkrivaju događaji koji se namerno potiskuju u okviru zvaničnog diskursa.

Konačno, bez obzira na to što sam roman sugeriše da nijedna verzija istine nije superiorna u odnosu na drugu, kroz Salimovu verziju čitalac se direktno stavlja u poziciju nekoga ko je deo određenog istorijskog trenutka, i upravo se u tome ogleda snaga fikcije u odnosu na zvaničnu istoriju. U Salimovoj nesigurnosti, kao i svesti o tome da je njegovo pamćenje varljivo i nepouzdano, čitalac može prepoznati poteškoće sa kojom se suočava svaki pojedinac u pokušaju da razume istoriju od koje je neodvojiv. Tako možemo zaključiti da se jedna od brojnih prednosti fikcije u odnosu na istoriografiju ogleda $u$ tome što ona upotpunjuje stvarnost, pružajući čitaocu priliku da je, poistovećujući se sa književnim likovima kao što je Ruždijev Salim, direktno proživi.

Napomena: Rad je nastao u okviru kursa Književnost, fikcija $i$ istina, tokom doktorskih studija na Filološkom fakultetu u Beogradu, pod mentorstvom prof. dr Kornelija Kvasa.

\section{Literatura}

Aristotel (2008). O pesničkoj umetnosti (M. N. Đurić, prev.). Beograd: Dereta.

Dhar, T. N. (1993). Problematizing History with Rushdie in Midnight's Children. Journal of South Asian Literature, 28, 93-111.

Gurnah, A. (2007). Themes and Structures in Midnight's Children. In A. Gurnah (Ed.), The Cambridge Companion to Salman Rushdie. Cambridge: Cambridge University Press.

Hutcheon, L. (1988). A Poetics of Postmodernism: History, Theory, Fiction. New York and London: Routledge.

Hutcheon, L. (1991). The Politics of Postmodernism. London: Routledge.

Kvas, K. (2011). Istina i poetika. Novi Sad: Akademska knjiga.

Markovski, M. P., Bužinjska, A. (2009). Književne teorije XX veka. Beograd: Službeni glasnik. 
Rushdie, S. (2010). 'Errata': or, Unreliable Narration in Midnight's Children. In Imaginary Homelands, Essays and Criticism 1981-1991 (pp. 22-25). London: Granta Books.

Ruždi, S. (2007). Imaginarni zavičaji (P. Šaponja, prev.). Polja, 448, LII, 27-34. Ruždi, S. (2019). Deca ponoći (S. Koljević i Z. Mutić, prev.). Beograd: Vulkan. Vukotić, A. (2018). Don DeLilo i poetika istorije. Novi Sad: Akademska knjiga. White, H. (1986). Tropics of Discourse: Essays in Cultural Criticism. Baltimore and London: The Johns Hopkins University Press.

\section{Milica S. Stanković}

Summary

\section{INDIVIDUAL AND OFFICIAL HISTORY IN SALMAN RUSHDIE'S MIDNIGHT'S CHILDREN}

Although it had been tackled since ancient times, the complex relation between history and fiction was not seriously problematized until the emergence of postmodernism in the second half of the twentieth century. One of the most significant literary works which contains all the important elements of the genre of historiographic metafiction defined by Linda Hutcheon in her famous work A Poetics of Postmodernism (1988) is undoubtedly Midnight's Children (1981) by Salman Rushdie. This paper provides a short analysis of Rushdie's novel, based on the most notable theoretical perspectives concerned with the problem of literary truth and the boundaries between historical and fictional discourse in postmodern fiction. The primary objective of the analysis is the way in which Rushdie's novel problematizes the existence of multiple histories, i.e. the official version of historical truth and its individual versions.

\section{Key words:}

history, fiction, truth, historiographic metafiction, official history, individual history 